\title{
Interpreting aggregate fluctuations looking at sectors ${ }^{2}$
}

\author{
Antonio Acconcia ${ }^{\mathrm{a}, *}$, Saverio Simonelli ${ }^{\mathrm{b}}$ \\ ${ }^{a}$ University of Napoli Federico II and CSEF, Napoli, Italy \\ ${ }^{\mathrm{b}}$ University of Napoli Federico II, EUI and CSEF, Napoli, Italy
}

Received 15 November 2006; accepted 1 December 2007

Available online 3 January 2008

\begin{abstract}
A dynamic factor model is used to investigate on the variability in labor productivity and hours across the 2-digit US manufacturing industries. Two kind of shocks emerge as quantitatively relevant during the postwar period. They can be reasonably interpreted as technology shocks to the production of equipment and economy-wide shocks. The former induces a positive correlation between productivity and hours growth rates in the durable-goods producing sector; the latter spurs a negative correlation in the nondurable-goods producing sector. Such evidence provides a novel interpretation of the aggregate near-zero correlation between the two variables.
\end{abstract}

(C) 2007 Elsevier B.V. All rights reserved.

JEL classification: C33; E32; O41

Keywords: Dynamic factor model; Long-run restriction; Sectors; Technology shock

\footnotetext{
${ }^{2}$ Previous versions of this paper have been presented at the University of Bari, the University of Hamburg, the University of Padova, ECARES, the University of Roma La Sapienza, the first CSEF-IGIER Symposium on Economics and Institutions (Capri, 2005), the 20th Annual Congress of the European Economic Association (Amsterdam, 2005), the 2005-2006 European Forum in Florence (EUI), the Royal Economic Society Annual Conference (Nottingham, 2006) and the RCEA Workshop on Applied Econometrics and Economics (Rimini, 2007).

*Corresponding author. Department of Economics, Via Cinthia, 45-80126 Napoli, Italy

E-mail addresses: antonio.acconcia@unina.it (A. Acconcia), saverio.simonelli@unina.it, savsimon@unina.it (S. Simonelli).
} 


\section{Introduction}

This paper investigates the cross-sectoral effects of economy-wide and sector-specific efficiency disturbances by estimating a dynamic factor model (DFM) with data on the 2-digit US manufacturing industries. First, we argue that the dynamic pattern of sectoral labor productivity is consistent with the assumption of two sources of long-run persistent disturbances, interpreted as investment-specific technical changes and sector-neutral innovations. Second, we interpret the near-zero correlation between aggregate labor productivity and employment growth rates as the overall outcome of both positive and negative correlations arising within the durable- and nondurable-goods producing sectors, respectively. The former is due to the investment-specific technical changes while the latter is traced to the sector-neutral productivity disturbances.

A body of recent empirical work on business fluctuations employs aggregate data in order to assess the relevance of technology shocks and to investigate the comovement between output and hours that is induced by technological change. The implicit assumption is that a one-sector model is sufficient in order to correctly interpret the business cycle. The common presumption is that an increase of employment after a technology shock should support the real-business-cycle (RBC) agenda, while the converse should support new Keynesian models. Restricting technology shocks to be solely responsible for permanent shifts in labor productivity, Galí (1999) shows how to recover such shocks using aggregate data and the structural vector autoregression (SVAR) procedure suggested by Blanchard and Quah (1989). In particular, he provides evidence that the technology shocks have a minor impact on economic fluctuations and determines a negative correlation between output and hours. Since the opposite holds for nontechnological disturbances, then the lack of unconditional correlation between aggregate labor productivity and hours is explained by reversing the effects of its sources, with respect to what is predicted by a standard one-sector RBC model. Similar findings are documented by Francis and Ramey (2005a, b) and Galí (2005).

Greenwood et al. $(1997,2000)$ argue that technological change embodied in the form of new equipment has been a main source of US postwar growth and business cycle. Moreover, Ireland and Schuh (2006) and Whelan (2003) suggest that a different treatment of consumption and investment is crucial for a better understanding of business cycles. In fact, growth in real investment has outpaced growth in real consumption throughout the entire postwar period, mainly because of the differential growth rate between durable and nondurable goods. By extending the Gali methodology to allow for both aggregate and investment-specific technology shocks, Fisher (2006) estimates an increase of aggregate hours after a positive investment shock and a contraction after an aggregate shock. The contribution of the two technology shocks to the fluctuations of output and hours is estimated to be substantially larger than is implied by Gali's estimates. Such new results are consistent with the difficulty in correctly recovering the technological component of the data with the Gali approach, as documented by Erceg et al. (2005).

This paper brings evidence across sectors to bear on the identification of technology shocks. By combining recent developments of dynamic factor analysis (Forni et al., 2000; Stock and Watson, 2002) and the SVAR approach as in Forni et al. (2007), we relate aggregate and sectoral data for the US to two distinct unobserved common factors; the latter is identified in terms of primitive shocks through long-run restrictions suggested by Galí and Fisher. Arguably, cross-sectoral responses to identified shocks provide useful information to 
investigate on the viability of the identification strategies and deliver a sectoral interpretation of the nearly zero correlation between aggregate labor productivity and hours worked.

As a first instance, we provide evidence that two dynamic factors characterize the common component of the labor productivity and hours growth rates across the 2-digit US manufacturing industries. The explanatory power of the common component for the variability of the two variables across industries is always greater than $50 \%$.

Given previous results, we make use of the Galí assumption to identify the cross-sectoral effects of two distinct types of innovations; one which influences permanently the aggregate (manufacturing) labor productivity - the technology shock - and the other which, by construction, has only a transitory effect on it - the non-technological shock. We find that a technological improvement induces positive and statistically significant longrun effects for almost all industries considered. With respect to this, sectoral results support the modelling of technological changes in terms of aggregate sector-neutral innovations. Looking at the effects of a non-technological shock, however, a drawback of such an identification approach emerges. We find that this shock - which by construction does not influence the long-run aggregate labor productivity - does influence the labor productivity of some industries, raising the possibility that the technology component of the data has not been correctly disentangled. A similar conclusion holds when restricting a weighted average of the labor productivity across industries.

Previous evidence can be rationalized by admitting that two distinct sources of innovation are relevant for the behavior of the labor productivity in the long run. When we identify the DFM by assuming distinct sector-neutral and sector-specific sources of fluctuations, we find that a (positive) investment-specific shock increases, both on impact and in the long run, the labor productivity of 7 out of 10 industries that are characterized by the production of durable goods. Conversely, we do not ascertain any effect when looking at the nondurable-goods producing sector. On aggregate, the long-run effect of the shock is statistically significant. Moreover, concerning the second source of fluctuations, we estimate widespread positive effects across sectors that indeed resemble those of sectorneutral innovations. We argue that these results support the identification assumption.

Sectoral-level data also suggest a novel interpretation of a well-known empirical finding, the near-zero correlation between aggregate labor productivity and employment growth rates. Assuming sector-neutral and investment-specific shocks, we provide evidence that the lack of aggregate correlation is the net effect of the positive correlation between the two variables in the durable-goods producing sector - conditional on the investment-specific innovations - and the negative correlation in the nondurable-goods producing sector conditional on the sector-neutral shocks. Thus, the aggregate evidence may be interpreted as the overall outcome of different sectoral dynamics induced by investment-specific and sector-neutral disturbances.

The rest of the paper is organized as follows. Section 2 presents the empirical model and the estimation strategy. In Section 3 we determine the number of statics and dynamic factors, while in Sections 4 and 5 we examine the sectoral implications of the two identification strategies. Finally, in Section 6 we summarize the main findings.

\section{The econometric framework}

The basic idea of factor analysis is to split a panel of data into two parts: the common component and the idiosyncratic component. The former is related to a small set 
of unobserved factors that affect the entire panel. The latter, instead, is assumed to capture shocks whose effects are not pervasive. The structural dynamic factor analysis allows the finding of distinct primitive shocks that determine the common component.

Let $X_{t}$ the $n \times 1$ vector of variables relevant for our study. Following the structural factor model of Forni et al. (2007) we consider a DFM of the form

$$
\begin{aligned}
& X_{t}=\Psi(L) f_{t}+v_{t}, \\
& f_{t}=\Phi(L) f_{t-1}+\varepsilon_{t},
\end{aligned}
$$

where $L$ denotes the lag operator, $\Psi(L)$ and $\Phi(L)$ are matrix lag polynomials, $f_{t}$ is an $m \times 1$ vector of unobserved dynamic factors, $v_{t}$ is an $n \times 1$ idiosyncratic disturbance vector and $\varepsilon_{t}$ is an $m \times 1$ vector of shocks to the dynamic factors (see, for instance, Forni et al., 2000, 2007; Stock and Watson, 2002; Bai and $\mathrm{Ng}$, 2007). The shocks in $\varepsilon_{t}$ and the idiosyncratic disturbance $v_{i, t}$ are assumed to be uncorrelated at all leads and lags; that is, $\mathrm{E}\left[\varepsilon_{t} v_{i, s}\right]=0$ for all $i, t, s$; a limited amount of correlation holds across the idiosyncratic terms for different $i$ and $j$.

When both the cross-section and the time-series dimensions of a panel tend to infinity, the common and idiosyncratic components are identifiable even though the disturbances $v_{t}$ are not mutually orthogonal. The main restriction is that the impact of each $v_{i, t}$ is concentrated on a finite number of cross-sectional units and tends to zero as the crosssectional dimension of the data tends to infinity. This feature of the DFM is of interest for our application. In fact, it would be unrealistic to assume a lack of cross-sectoral correlation induced by idiosyncratic disturbances when a set of industries is involved with strong relationships.

Inverting the VAR representation for the evolution of the factors and substituting into the first equation of the DFM yields the moving average representation for $X_{t}$ in terms of current and lagged shocks $\varepsilon_{t}$ and the idiosyncratic disturbances $v_{t}$ :

$$
X_{t}=\Gamma(L) \varepsilon_{t}+v_{t}
$$

Our main goal consists in deducing the structural shocks driving comovements across sectors in labor productivity and hours from the $m$ dynamic factor innovations $\varepsilon_{t}$. Thus, let $\eta_{t}$ denote the $m$ structural shocks to the dynamic factors. As usual in SVAR analysis we assume that $\eta_{t}=R \varepsilon_{t}$, where $R$ is an $m \times m$ invertible matrix, and that $\mathrm{E}\left[\eta_{t} \eta_{t}^{\prime}\right]=I$. In general, the identification consists of selecting $R$ such that economically motivated restrictions on the matrix $\Gamma(L) R^{-1}$ are satisfied; in particular, since $R$ is an orthonormal matrix then $m(m-1) / 2$ restrictions are required. It follows that adopting a structural dynamic factor approach, we can use information on $n$ variables to identify $m$ shocks, with $n$ much larger than $m$. This implies that even a small set of economically motivated restrictions may generate testable over-identified restrictions. In the following, long-run restrictions will be used to recover the $n \times m$ impulse response functions for $X_{t}$ with respect to the structural shocks.

\subsection{The estimation strategy}

Let $s$ be the degree of $\Psi(L)$ and consider the vector $F_{t}=\left(f_{t}^{\prime} f_{t-1}^{\prime} \ldots f_{t-s}^{\prime}\right)^{\prime}$. Each term in $F_{t}$ denotes a static factor; a subset of lags of $f_{t}$ enters $F_{t}$ if not all dynamic factors appear with $s$ lags. Thus the dimension of $F_{t}$ is $r \times 1$, where $m \leqslant r \leqslant m(s+1)$. Let us consider the 
following static version of the DFM (Stock and Watson, 2002):

$$
\begin{aligned}
& X_{t}=\Lambda F_{t}+v_{t}, \\
& F_{t}=\Omega F_{t-1}+S \varepsilon_{t},
\end{aligned}
$$

where $\Lambda$ is an $n \times r$ matrix of loadings and $S$ is an $r \times m$ matrix. Our empirical strategy consists of three steps:

- First, we estimate the relevant number of static and dynamic factors. Formal tests proposed by Onatski (2007) and Bai and $\mathrm{Ng}$ (2007) will be used to determine, respectively, $r$ and $m$.

- Second, we estimate the static version of the DFM. By adopting the strategy proposed by Forni et al. (2007) we estimate the static factors as the first $r$ principal components of $X_{t}$; then we recover the factor loadings estimates by regressing $X_{t}$ on the estimated factors:

$$
\widehat{\Lambda}=\sum_{t=1}^{T} X_{t} \widehat{F}_{t}^{\prime}\left(\sum_{t=1}^{T} \widehat{F}_{t} \widehat{F}_{t}^{\prime}\right)^{-1} .
$$

Given $\widehat{F}_{t}$, from the VAR describing the evolution of the (estimated) factors it follows that

$$
\begin{aligned}
\widehat{\Omega} & =\sum_{t=2}^{T} \widehat{F}_{t} \widehat{F}_{t-1}^{\prime}\left(\sum_{t=2}^{T} \widehat{F}_{t-1} \widehat{F}_{t-1}^{\prime}\right)^{-1}, \\
\widehat{\Sigma} & =\frac{1}{T-1} \sum_{t=2}^{T} \widehat{F}_{t} \widehat{F}_{t}^{\prime}-\widehat{\Omega}\left(\frac{1}{T-1} \sum_{t=2}^{T} \widehat{F}_{t-1} \widehat{F}_{t-1}^{\prime}\right) \widehat{\Omega}^{\prime}, \\
\widehat{S} & =B^{-1} H,
\end{aligned}
$$

where $H$ is a diagonal matrix containing the square roots of the first $m$ largest eigenvalues of $\widehat{\Sigma}$ and $B$ is the $r \times m$ matrix whose columns are the eigenvectors corresponding to those eigenvalues. Moreover, $\Lambda, \Omega$ and $S$ in (1) and (2) are replaced by corresponding estimates and, by means of the Kalman filter, we re-estimate the factors and get the estimates of the common shocks.

- Third, we determine the impulse responses with respect to the primitive common shocks $\eta_{t}$ and the relative confidence intervals. By inverting (2) and substituting into (1) for $F_{t}$ it follows that

$$
\begin{aligned}
X_{t} & =\widehat{\Lambda}(I-\widehat{\Omega} L)^{-1}{\widehat{S \varepsilon_{t}}}_{t}+v_{t} \\
& =\widehat{\Gamma}(L) R^{-1} \eta_{t}+v_{t} .
\end{aligned}
$$

For any $R$, the previous equation delivers the impulse responses. ${ }^{1}$ Moreover, given the estimates of the factor model based on the observations, we obtain confidence intervals for the impulse responses by a bootstrapping procedure. In particular, we generate 500 new series for the static factors, $F_{t}^{(j)}$, where each series $j$ is generated as follows:

\footnotetext{
${ }^{1}$ The entries of $R$ depend on the identifying assumption; we will discuss later this issue.
} 
(i) we extract with replacement from the estimated vector $\widehat{S \varepsilon}_{t}$ to generate a new series $\widehat{S \varepsilon}_{t}^{j}$; (ii) parameter estimates based on observations and the ${\widehat{S \varepsilon_{t}}}_{t}^{j}$ are used to compute $F_{t}^{(j)}$. For any $F_{t}^{(j)}$, a new estimate of $\Lambda$ and then a new set of identified impulse responses are recovered. The $95 \%$ confidence intervals are calculated according to the empirical distribution of impulse responses.

\section{The number of common factors}

Since Lilien (1982) and Long and Plosser (1983) the relevance of aggregate and sectoral shocks in business cycle has been the focus of growing interest among economists. Long and Plosser (1987) provide a quantitative assessment of the two potential sources of fluctuations through a standard factor analysis, under the assumption that all of the short-run comovement is attributed to the common factors, which are indeed interpreted as aggregate disturbances. In particular, the explanatory power of the estimated factors with respect to the variables considered suggests whether a factor may be well characterized as a common disturbance. Results for sectoral industrial output in US are consistent with the existence of one aggregate disturbance whose explanatory power is, however, limited. Actually, as more factors are considered, each tends to be correlated with only one or two industries at a time. ${ }^{2}$

Recent developments of factor analysis allow the determination, through formal statistical tests, of the number of relevant primitive shocks or dynamic common factors characterizing a panel. Moreover, given an estimate of the common component, economically motivated restrictions allow for the identification of the sources of the shocks, as is usual in the SVAR literature. Impulse responses provide information on whether identified shocks determine homogeneous or heterogeneous effects across sectors. In this way, we disentangle aggregate versus sector-specific sources of fluctuations.

In the following, we deal with a panel of US annual data on labor productivity and employment relative to 18 2-digit SIC manufacturing industries, the durable- and nondurable-goods producing sectors and the manufacturing sector as a whole. ${ }^{3}$ Thus, $X_{t}$ is an $42 \times 1$ vector. Employment is measured as hours worked, while productivity is measured as a deflated value of production over employment. The time span of the data is 1949-2000. Each variable enters $X_{t}$ as a log difference, where this choice is supported by standard unit root tests. ${ }^{4}$

\footnotetext{
${ }^{2}$ This conclusion is consistent with more recent results departing from different analytical perspectives. Horvath and Verbrugge (1997), for instance, conclude that at medium term independent sectoral shocks are prominent to explain forecast error variance for aggregate output in the US. Campbell and Kuttner (1996), Davis and Haltiwanger (1999) and Phelan and Trejos (2000) provide evidence that intersectoral or spatial allocative shocks come out as the main driving force behind job reallocation and they account for a large fraction of employment variance. The contribution of aggregate shocks, instead, tends to be modest. A similar conclusion also arises allowing for non-linearity of sectoral shifts (Pelloni and Polasek, 2003).

${ }^{3}$ Note that looking at high-frequency data (for instance, monthly innovations) reduces the potential role for common shocks if these shocks influence some sectors only with some delay. Looking instead at low-frequency data (for instance, yearly observations) may result in mislabelling some portion of sectoral shocks that have propagated to other sectors within the year as common disturbances (Long and Plosser, 1987). Thus, our choice of annual data is consistent with the following strategy: (i) estimate the DFM under assumptions favorable to common shocks; (ii) identify the DFM to disentangle aggregate versus sector-specific-sources of fluctuations.

${ }^{4}$ We test the null hypothesis of unit root against the alternative of trend stationarity adopting the Dickey-Fuller tests. Detailed results are available from the authors upon request.
} 
Table 1

The number of static and dynamic factors

Onatski (2007) test on $r$

\begin{tabular}{lll}
\hline & $\mathrm{H}_{0}: r=1$ & $\mathrm{H}_{0}: r=2$ \\
& $\mathrm{H}_{1}: 1<r \leqslant r_{\max }$ & $H_{1}: 2<r \leqslant r_{\max }$ \\
Statistics & 10.61 & 2.93 \\
$95 \%$ Critic value & 8.59 & 8.29 \\
Bai and Ng (2007) test on $m$ & & \\
& $\widehat{q}_{3}$ & $\widehat{q}_{4}$ \\
& 2 & 2 \\
\hline
\end{tabular}

Note: The first part of the table refers to the Onatski (2007) test on the number of static factors $(r)$. In the first row we report the approximate 95th percentiles of the statistics for testing $r$ factors versus an alternative of more than $r$ but less than $r_{\max }$ factors (with $r_{\max }=10$ ), while in the second row we report the values of the test statistic. The second part of the table reports the results of the Bai and $\mathrm{Ng}$ (2007) test on the number of the dynamic factors for $r=2\left(q_{3}\right.$ and $q_{4}$ are defined in the main text $)$.

The number of relevant static factors is estimated by applying the approach suggested by Onatski (2007). Given an a priori maximum number of factors, $r_{\max }$, the null hypothesis of the test is $r=k$ while the alternative is $k<r=k+s \leqslant r_{\max } .5$ Thus, we apply the test sequentially starting from the null hypothesis of $r=1$ and assuming $r_{\max }=10$. Table 1 reports our results. When the null is given as $r=1$, the test clearly suggests that this null should be rejected. However, we cannot reject the null hypothesis of $r=2$. The values of the statistic are given, respectively, as 10.61 and 2.93; the former is above the critical value 8.59 , relative to a $5 \%$-size test, while the latter is far below the appropriate critical value of 8.29. Thus, we conclude that two static pervasive factors drive the time series under consideration. ${ }^{6}$

Since the number of static factors provides an upper bound on the number of dynamic factors, it follows that $m$ is either 1 or 2. In particular, an estimate of $m$ is obtained by applying the test proposed by Bai and $\mathrm{Ng}$ (2007). Given $\widehat{r}=2$, we find that the two static factors are dynamically distinct; that is, $\widehat{m}=2$ (Table 1$){ }^{7}$

\footnotetext{
${ }^{5}$ Let $\widetilde{X}_{1}, \ldots, \widetilde{X}_{T / 2}$ be an artificial new data set obtained by splitting the sample of observations into two parts of equal length, multiplying the second part by the imaginary unit (the square root of -1 ) and adding up the resulting two parts. The test statistic of the null $r=k$ equals

$$
\max _{k<k+s \leqslant r_{\max }}\left(\gamma_{k+s}-\gamma_{k+s+1}\right) /\left(\gamma_{k+s+1}-\gamma_{k+s+2}\right)
$$

where $\gamma_{k+s}$ is the $(k+s)$ th largest eigenvalue of the sample covariance matrix of the new data set.

${ }^{6} \mathrm{An}$ alternative approach to the estimate of the number of static factors is through the method proposed by Bai and $\mathrm{Ng}$ (2000). However, the authors show that the test is only reliable when both $N$ and $T$ are extremely large.

${ }^{7}$ Let $c_{i}$ be the $i$ th largest eigenvalue of the covariance matrix of $\widehat{S \varepsilon}_{t}$. Bai and $\mathrm{Ng}$ (2007) suggest two different test statistics, namely $q_{3}$ and $q_{4}$, defined as $q_{3}=\min \left(k \in k_{3}\right)$ and $q_{4}=\min \left(k \in k_{4}\right)$, where

$$
\begin{aligned}
& k_{3}=\left\{k:\left(\frac{c_{k+1}^{2}}{\sum_{j=1}^{r} c_{j}^{2}}\right)^{1 / 2}<\tau / \min \left(N^{a}, T^{a}\right)\right\}, \\
& k_{4}=\left\{k:\left(\frac{\sum_{j=k+1}^{r} c_{j}^{2}}{\sum_{j=1}^{r} c_{j}^{2}}\right)^{1 / 2}<\tau / \min \left(N^{a}, T^{a}\right)\right\} .
\end{aligned}
$$
}

In our case both statistics point at $m=2$. 
Table 2

Percentage of variance explained by the first two factors

\begin{tabular}{lll}
\hline Industry & Labor productivity & Hours \\
\hline Manufacturing & 0.78 & 0.91 \\
Nondurable goods & 0.54 & 0.91 \\
Food and kindred products & 0.46 & 0.57 \\
Textile mill products & 0.60 & 0.83 \\
Apparel & 0.64 & 0.81 \\
Paper and allied products & 0.54 & 0.82 \\
Printing, publishing and allied industries & 0.64 & 0.58 \\
Chemicals and allied products & 0.76 & 0.75 \\
Petroleum refining and related products & 0.63 & 0.55 \\
Rubber and miscellaneous plastic products & 0.67 & 0.91 \\
Durable goods & 0.76 & 0.90 \\
Lumber and wood products & 0.57 & 0.87 \\
Furniture and fixtures & 0.48 & 0.91 \\
Stone, clay, glass, and concrete products & 0.60 & 0.90 \\
Primary metal industries & 0.77 & 0.86 \\
Fabricated metal products & 0.58 & 0.86 \\
Machinery (except electrical) & 0.70 & 0.78 \\
Electrical and electronic machinery & 0.69 & 0.79 \\
Transportation equipment & 0.61 & 0.77 \\
Measuring and controlling instruments & 0.57 & 0.78 \\
Miscellaneous manufacturing industries & 0.59 & 0.77 \\
\hline
\end{tabular}

Note: The table describes the share of the variance of the growth rates of labor productivity and hours worked explained by the common component.

Drawing on previous evidence, Table 2 reports the goodness of fit of the projection of each considered variable onto the first two principal components of the data panel. Across industries, the common component comes out to explain at least $50 \%$ of the variance of labour productivity and hours. ${ }^{8}$ In particular, comparing the durable- and nondurablegoods sectors, it follows that the two common factors explain a substantially larger proportion of the variability of labor productivity within the durable-goods sector.

\section{Aggregate sources of fluctuations}

Much of the recent empirical work on business fluctuations rests on the identification assumption, firstly put forward by Galí (1999), that the long-run variability of aggregate labor productivity is traced to a single source of shocks, interpreted as technological change. Other disturbances are restricted to have a purely transitory influence. The sign of the correlation between labor productivity and employment induced by technology shocks is related to which class of economic models correctly interprets the dynamic behavior of market economies. In particular, the evidence that technology shocks have a negligible impact on economic fluctuations and induce a negative correlation between output and hours is viewed as conflicting with the idea of the technology-driven business cycle (Galí, 1999).

\footnotetext{
${ }^{8}$ The only two exceptions concern the labor productivity of the food and kindred products and furniture and fixtures industries.
} 

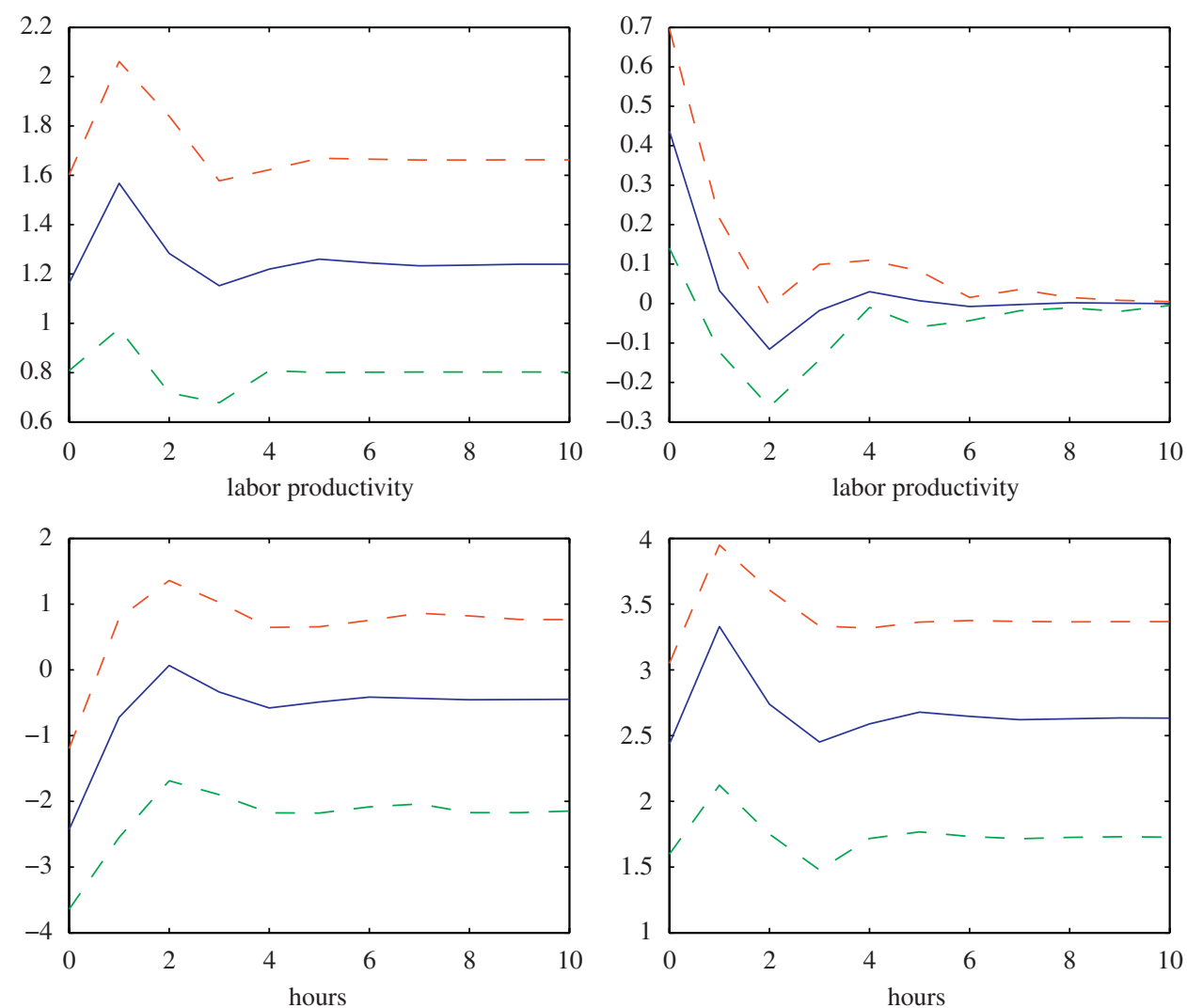

Fig. 1. Impulse response functions relative to the manufacturing sector under the Galí assumption. Plots on the left-hand side report the effects of a technology shock while plots on the right-hand side report the effects of a non technology shock: that is, a shock with transitory effects on aggregate labor productivity.

By assuming that technology shocks can be recovered as the sole source of permanent shifts in aggregate labor productivity, the moving average representation of our DFM delivers the impact of technology and non-technological shocks by choosing $\vartheta$ such that $\operatorname{Dvec}\left[\widehat{\Gamma}(1) R^{-1}(\widehat{\vartheta})\right]=0 . \widehat{\Gamma}(1)$ is the matrix of estimated long-run impulse responses and $D$ is an $1 \times 84$ indicator vector with all elements equal to zero, except one associated with the response of the aggregate labor productivity to the non-technological shock. ${ }^{9}$

Fig. 1 shows impulse responses for aggregate employment and labor productivity to the identified shocks. ${ }^{10}$ It is noteworthy that our results look quite similar to those of Galí (1999) and others, despite the fact that we estimated a DFM instead of a VAR and used annual rather than quarterly data. In particular, we find that just after a technology shock hours worked declines, supporting the theoretical predictions of both new Keynesian models or less orthodox versions of flexible price models. ${ }^{11}$

\footnotetext{
${ }^{9}$ Note that since the matrix $R$ depends on the single parameter $\vartheta$ exact identification requires a single restriction.

${ }^{10}$ Note that for aggregate we refer to the manufacturing sector.

${ }^{11}$ Similar evidence is provided by Kiley (1997), Francis and Ramey (2005a, b) and Galí and Rabanal (2005). In particular, Kiley investigates the dynamic effects of technology disturbances at sectoral level. However, differently
} 
If the technology (permanent) component of the data has been correctly disentangled, then we can conjecture on its nature, either aggregate or sector specific, looking at the long-run effects of technology shock on the labor productivity across sectors. In particular, if the identified shocks are genuine aggregate shocks then productivity should go up in almost all industries following a positive technology shock, suggesting that it may indeed be interpreted as a sector-neutral technological improvement. At the same time, evidence about the long-run effects of a transitory, non-technological shock should inform on whether the technological component has been completely recovered. Assuming that such shock is aggregate in nature would imply that it may affect the sectoral labor productivity only in the short run; thus, estimation of permanent variations across sectors should be interpreted as a mark against the aggregate-data identification strategy. In principle, one might interpret the transitory, non-technological shock as an intersectoral allocative shock. The aggregate long-run neutrality would imply, however, that this source of fluctuations determines differential permanent effects across industries that exactly cancel out on aggregate. Hence, sectoral evidence provides useful information to question the reliability of the identification assumption.

Fig. 2 shows the responses of labor productivity after a (positive) technology shock for the 18 manufacturing industries, the durable- and nondurable-goods producing sectors and the manufacturing sector as a whole. The figure shows that, for 16 out of 18 industries, the shock produces a positively and statistically significant effect in the long run. Particularly, a technology shock determines quantitatively relevant increments of the labor productivity mainly for chemicals and allied products, rubber and miscellaneous plastic products, transportation equipment and electrical machinery. At a more aggregate level, the figure suggests that the impact of a technology shock is quantitatively more relevant for the durable-goods sector than the nondurable-goods one. The labor productivity increment of the former (latter) is estimated to be higher (lower) than that of the manufacturing sector as a whole. Food and kindred products and primary metal industries are the only two industries that do not appear to be affected by a technology shock either in the short run or in the long-run. Overall, our results would suggest that the identification strategy correctly isolates the effect of shocks, which can be labelled as aggregate, sectorneutral technology shocks.

The support of the Galí methodology weakens when we look at the effects of the nontechnological shock. This shock, by construction, does not influence the aggregate labor productivity in the long run. The impulse responses shown in Fig. 3 clearly show, however, that for many industries such shock has a statistically significant long-run impact. This is mainly true for four of the eight industries characterized by the production of nondurable goods (paper and allied products; printing, publishing and allied industries; chemicals and allied products; petroleum refining and related products) and for five out of 10 of the durable-goods industries (stone, clay, glass and concrete products; primary metal industries; fabricated metal products; machinery; transportation equipment). In those cases, the shock determines a positive and statistically significative effect both on impact

\section{(footnote continued)}

from the present paper, the two components of the data are recovered looking at each sector separately. Hence, the potential impact of cross-sectoral linkages are not taken into account. Conversely, Chang and Hong (2005) show that for a large number of 4-digit US manufacturing industries technological progress significantly increases hours in the short run, if technology shocks are identified restricting the long-run behavior of total factor productivity. 


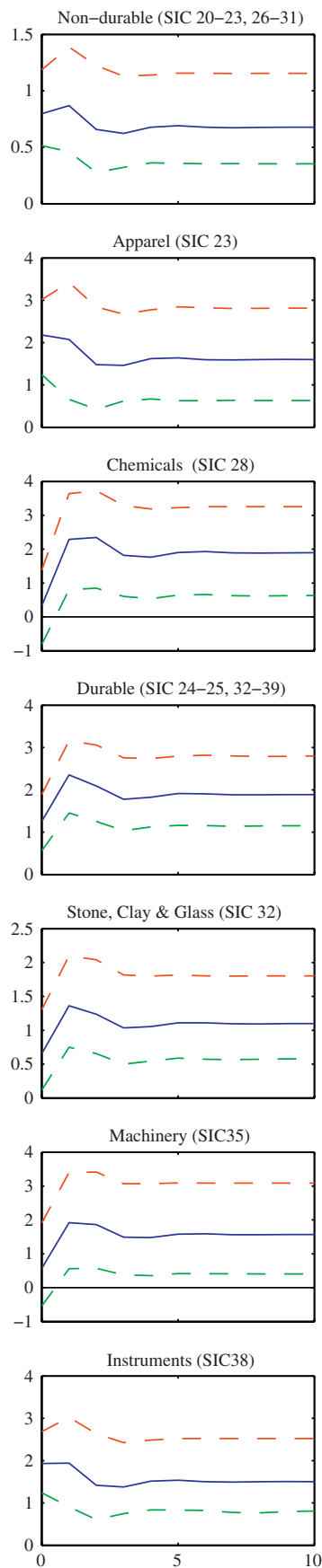
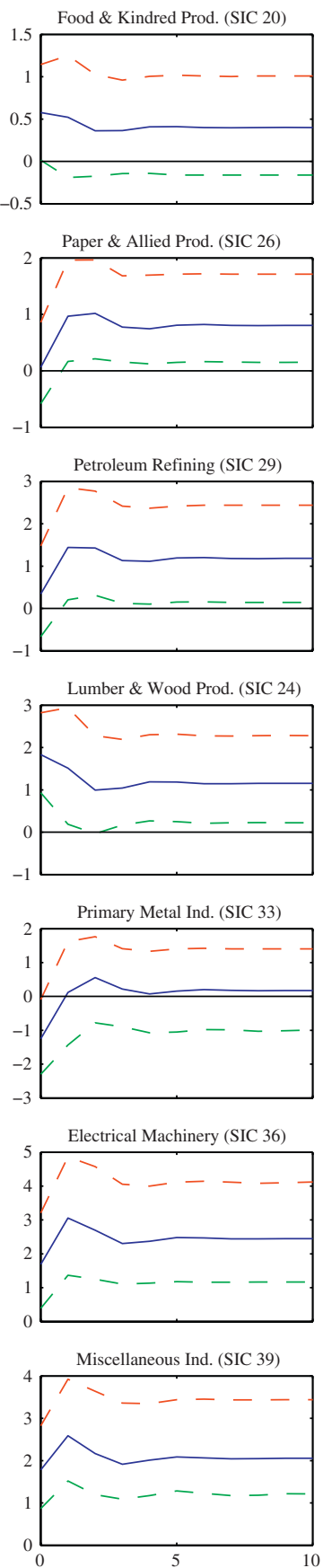

Fig. 2. Impulse responses of the labor productivity across industries after a technology shock, under the Galí assumption. 


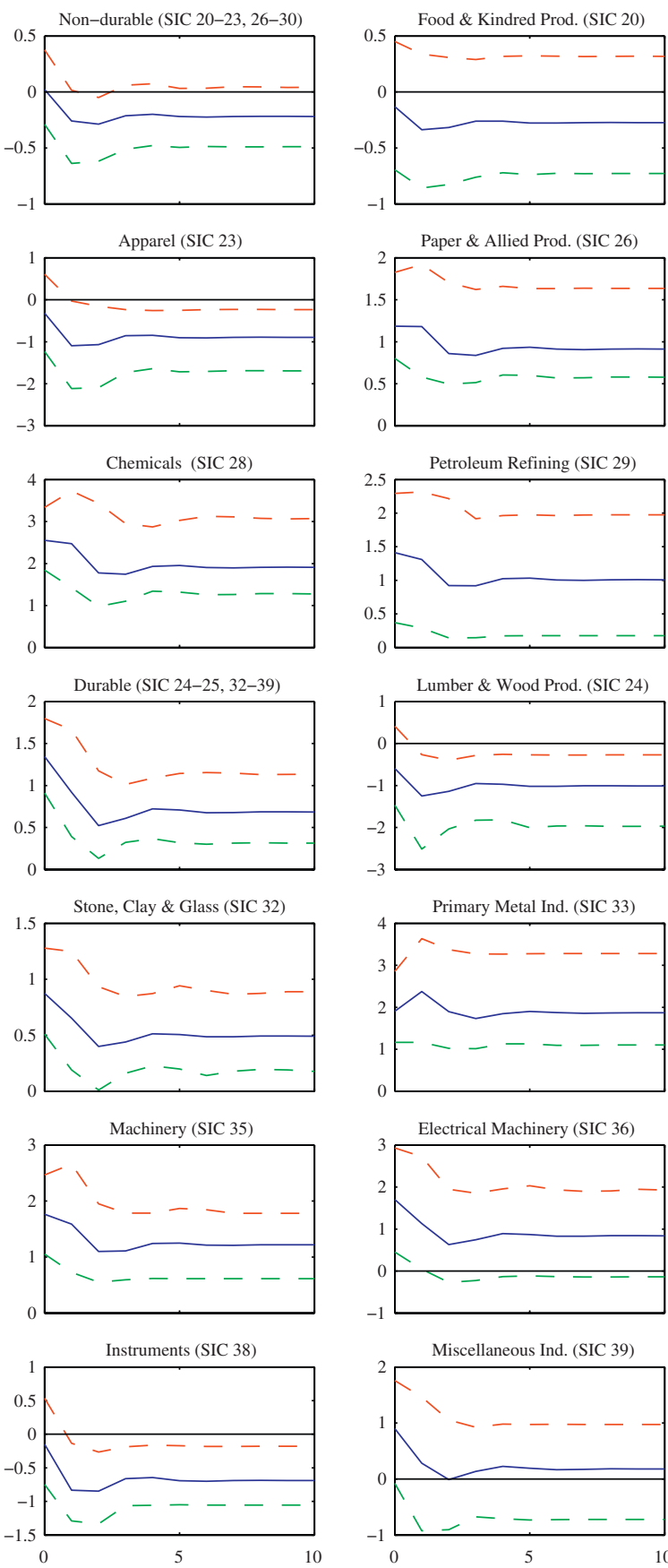
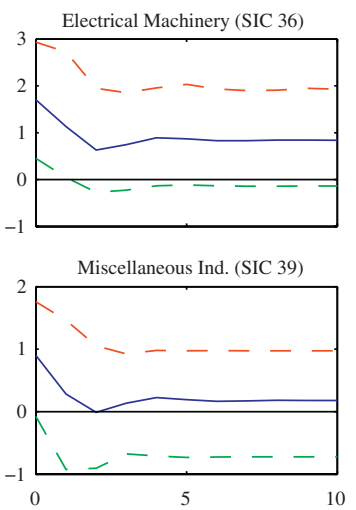

Fig. 3. Impulse responses of the labor productivity across industries after a non-technology shock, under the Galí assumption. 

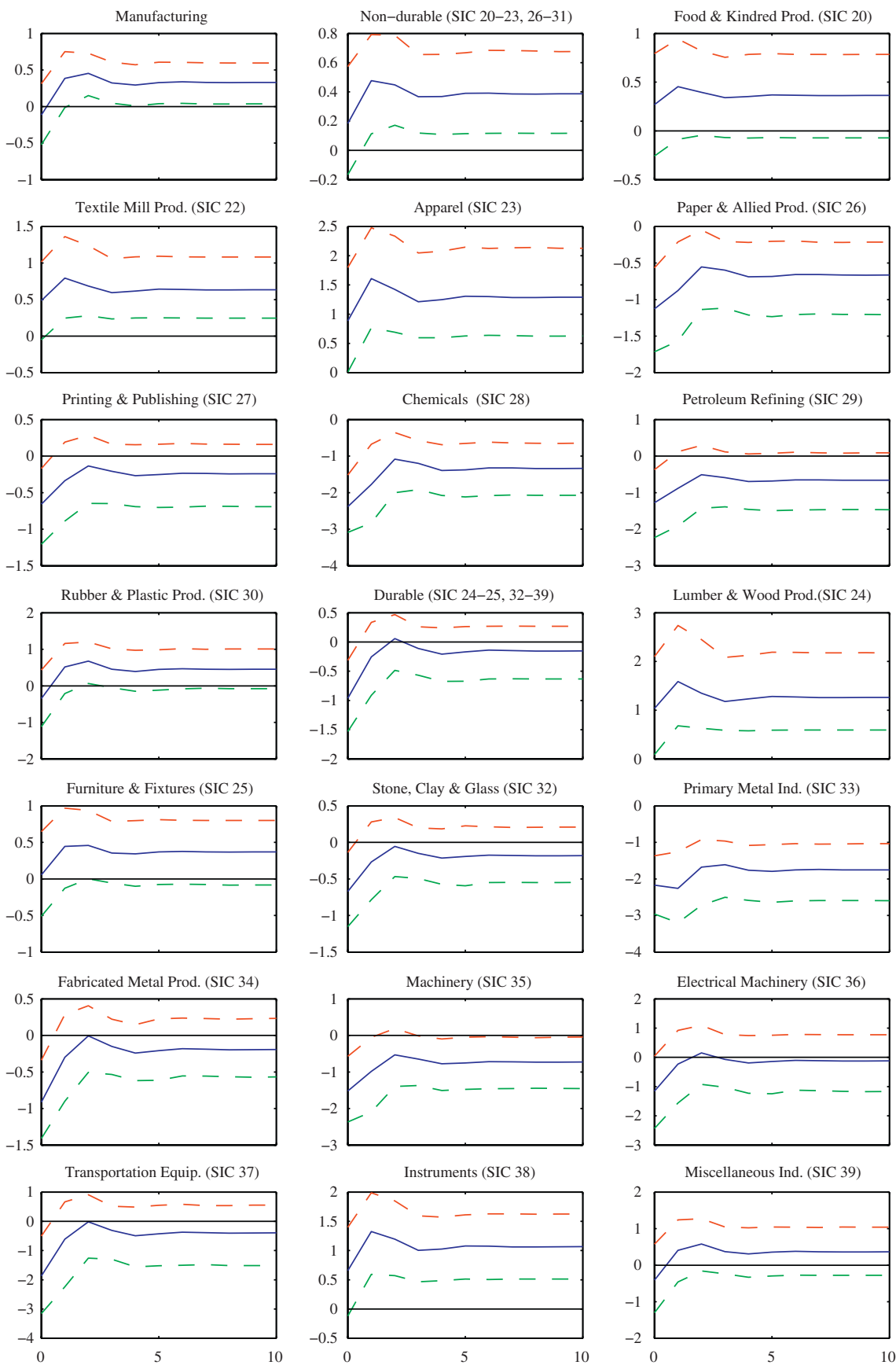

Fig. 4. Impulse responses of the labor productivity to a shock determining the minimum long-run impact on sectoral labor productivities. 
and in the long run. At a more aggregate level, it happens that after a non-technological shock, the labor productivity in the durable-goods sector rises on impact and stabilizes to a positive and statistically significant value in the long run. The results are also consistent with the assumption that the nondurable-goods producing sector does not appear to be affected at all by the shock. Thus, it may be the case that the technological component of the data has not been correctly disentangled. Indeed, the identification strategy seems to neglect shocks that mainly affect the production of equipment.

The empirical approach proposed above rests on the view that if we identify the effect of a shock by imposing a long-run restriction on a given aggregate variable, then the same restriction should characterize that variable for each sector. This argument appears to be quite plausible if one interprets, as usual, the transitory shock as an aggregate nontechnological shock. It can be argued, however, that the long-run neutrality across sectors is a requirement that is too strong to question the above identification approach. A weaker interpretation would allow permanent shifts in labor productivity across sectors after a non-technological shock. The aggregate long-run neutrality would imply, however, that sectors should respond symmetrically to this source of variability. Thus, we now follow a different route by defining a non-technological shock for a sectoral economy as one determining the minimum long-run impact on the weighted average, across industries, of the labor productivity. Technically, this identification assumption implies a value of $\widetilde{\vartheta}$ such that

$$
\widetilde{\vartheta}=\underset{\vartheta}{\arg \min }\left\{\operatorname{vec}\left[\widehat{\Gamma}(1) R^{\prime}(\vartheta)\right]^{\prime} \widetilde{D}^{\prime}\right\}\left\{\widehat{\operatorname{Var}}\left(\widetilde{D} v e c\left[\widehat{\Gamma}(1) R^{\prime}(\vartheta)\right]\right)\right\}^{-1}\left\{\widetilde{D} \operatorname{vec}\left[\widehat{\Gamma}(1) R^{\prime}(\vartheta)\right]\right\},
$$

where $\operatorname{Var}(\cdot)$ denotes the variance operator and $\widetilde{D}$ is an $18 \times 84$ indicator matrix, with all elements equal to zero except those relating to industrial labor productivity responses to the non-technological shock. ${ }^{12}$ The main message of Fig. 4 is that such a shock permanently affects the aggregate labor productivity and, therefore, cannot be labelled as a pure allocative shock. This finding reinforces our main conclusion that the dynamic behavior of the labor productivity across US sectors does not support the assumption of a single, aggregate source of permanent shocks. ${ }^{13}$

\section{Neutral and sector-specific shocks}

Some authors have recently pointed out that multi-sector neoclassical growth models provide a better description of the business cycle phenomena and long-run behavior of the US economy than the traditional one-sector model. In particular, models based on different consumption- and equipment goods producing technologies, as suggested by Greenwood et al. (1997), are consistent with the negative correlation between price and quantity of new equipment at high and low frequencies (Greenwood et al., 2000), the

\footnotetext{
${ }^{12}$ The estimate of the weighting matrix is the variance-covariance matrix of the impulse responses obtained through the bootstrapping procedure.

${ }^{13}$ The main conclusion of this section is based on considering two static and dynamic factors. As shown before, this choice, determined by appropriate tests, is also appealing because it implies on aggregate results qualitatively similar to those reported by different authors employing the SVAR approach. Note, however, that such a conclusion is not much sensitive to the number of static factors: even assuming values of $r$ larger than two, the labor productivity of some manufacturing industries appears to be permanently affected by a non-technology shock. Detailed results for values of $r$ up to seven are available from the authors upon request.
} 
comovement in sectoral employment and output following changes in relative productivities (Hornstein and Praschnik, 1997) and the constant nominal and trending real shares of expenditure on consumption versus investment goods (Whelan, 2003; Ireland and Schuh, 2006). ${ }^{14}$ In general, within these models a prominent role is assigned to technological progress in the production of durable goods, which exceeds that in the rest of the economy.

Following this line of research, we now assume that innovations to the dynamic factors depend on sector-specific shocks, which originate in the investment-goods producing industries, and sector-neutral shocks, which may be thought of as economy-wide efficiency disturbances. Greenwood et al. (2000) and Fisher (2006) provide, respectively, the theoretical framework for modelling the investment-specific technical change and the empirical assumptions to identify the effects of the two shocks accordingly. We now outline the main components of the identification strategy.

The production side of the economy is composed of two sectors - the equipment and consumption sectors - where competitive firms operate under the assumption that inputs can be freely allocated across sectors. Production in the consumption sector takes place according to the production function $F(\cdot, z)$, where $z$ is a measure of sector-neutral productivity, and production in the equipment sector takes place according to $q F$, where $q$ is a measure of the state of the technology for producing equipment. Thus, changes in $q$ represent investment-specific technological changes. Both (the log differences of) $z_{t}$ and $q_{t}$ are driven by two mutual, orthogonal shocks. Finally, a representative agent is assumed to maximize the expected value of lifetime utility. ${ }^{15}$

It can be shown that a competitive equilibrium is characterized by the following restriction: $p_{t} q_{t}=1$, where $p_{t}$ denotes the relative price of investment goods. Thus, the investment-specific technology shock has permanent effect on $p_{t}$. This is the long-run restriction that allows for the identification of the two common sources of variability in output and hours. Moreover, a further implication of the theoretical framework is that the long-run impact of an investment-specific shock on aggregate labor productivity is proportional to its effect on the relative price of investment goods. The specific constant of proportionality depends on factor shares in the production functions. By assuming one capital good, this implies a simple linear restriction on the coefficients of $\Gamma(L)$ relative to the aggregate labor productivity equation. ${ }^{16}$

In order to identify our DFM in terms of the above restrictions, we consider the price of equipment series, constructed by Cummins and Violante (2002), as a ratio to the consumption-goods deflator. First, consider the aggregate responses to the investmentspecific shock, shown on the right-hand side of Fig. 5. For both labor productivity and hours, the effect of the shock is positive and statistically significant on impact and in the long run. These results agree with those of Fisher (2006). Consider now the effects of the sector-neutral shock, shown on the left-hand side of the figure. The labor productivity responds positively both on impact and in the long run and the effects of the shock are

\footnotetext{
${ }^{14} \mathrm{As}$ regards the role of intersectoral linkages in explaining output and employment comovements see, for instance, Hornstein and Praschnik (1997), Horvath (2000), Boldrin et al. (2001). In particular, a crucial element for Hornstein and Praschnik (1997) is that nondurable goods serve as intermediate inputs in the production of durable goods.

${ }^{15}$ Whelan (2003) shows how the distinction between neutral and investment-specific technological change can be reformulated as one between consumption-specific and investment-specific technological change.

${ }^{16}$ We refer to Fisher (2006) for further details.
} 



Fig. 5. Impulse responses of relative price, aggregate labor productivity and aggregate hours. On the right-hand side we report the effects of an investment-specific shock while on the left-hand side those of a sector-neutral shock.

always statistically significant. Conversely, hours respond negatively on impact before returning back toward zero. The behaviors of hours and labor productivity after a neutral shock are very similar to those we recovered in Section 4 (see Fig. 1), as well as to those that Galí (1999) and Fisher (2006) estimated as being caused by an aggregate technology shock. ${ }^{17}$

Looking at the 2-digit SIC manufacturing industries, Fig. 6 documents statistically significant, positive, long-run effects for 15 of the 18 labor productivities after a positive sector-neutral shock. Consistently, the effect of the shock is also estimated to be positive for the durable- and nondurable-goods producing sectors and the manufacturing sector. The main exception relates to primary metal industries that appear not to be affected at all

\footnotetext{
${ }^{17}$ The responses of the relative price of equipment (not reported) are in line with what is expected. Besides technology shocks, note that time-varying mark-ups also may induce persistent variations in prices. In this case, the identifying strategy correctly recovers the technology component of the data to the extent that there is no longrun tendency for mark-ups to decline more in producing equipment goods than in producing consumption goods. Actually, we conjecture that relative variations in mark-ups might be reasonable for short periods and for specific industries (see Ramey, 1996).
} 


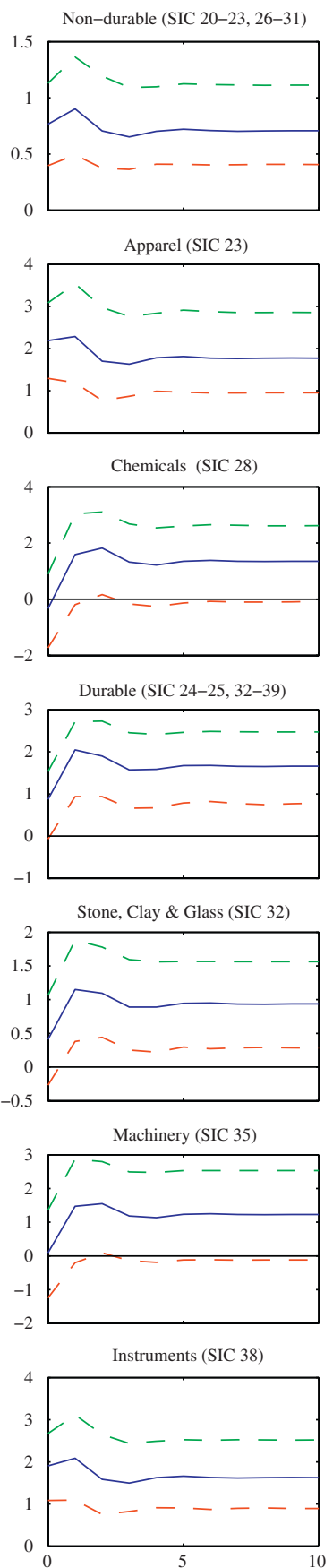

Food \& Kindred Prod. (SIC 20)
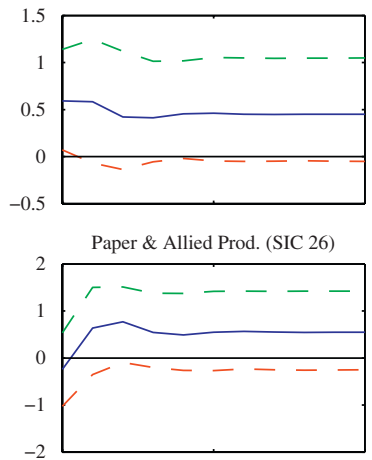

Petroleum Refining (SIC 29)

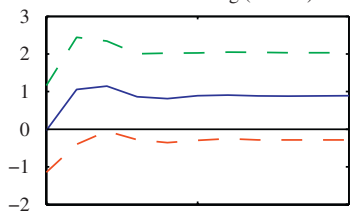

Lumber \& Wood Prod. (SIC 24)



Primary Metal Ind. (SIC 33)

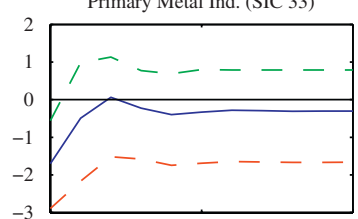

Electrical Machinery (SIC 36)

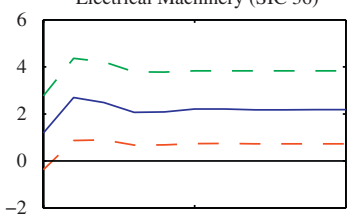

Miscellaneous Ind. (SIC 39)

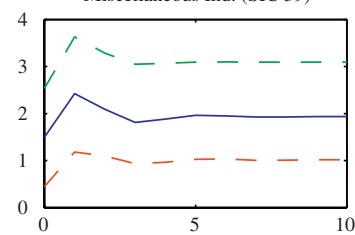

Fig. 6. Impulse responses of the labor productivity across industries to a sector-neutral shock. 



Rubber \& Plastic Prod. (SIC 30)
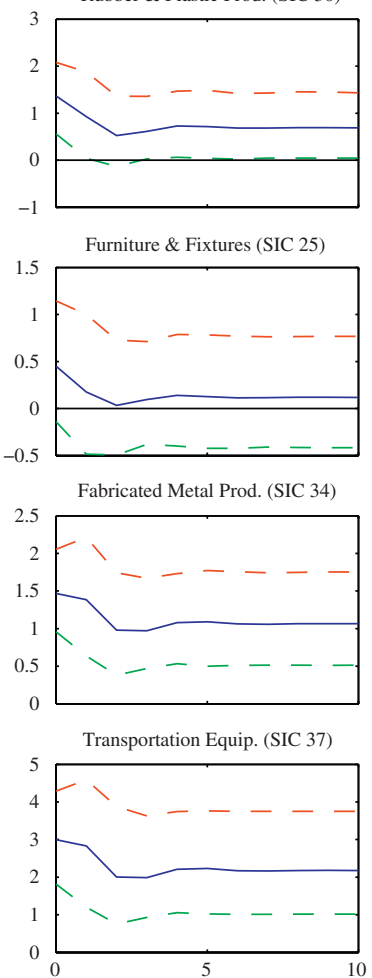

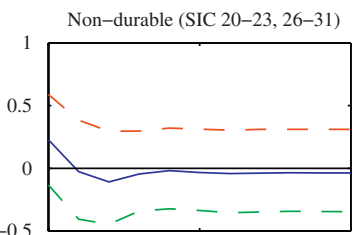

Apparel (SIC 23)
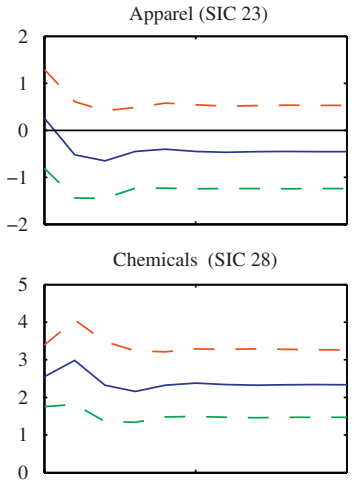

Durable (SIC 24-25, 32-39)
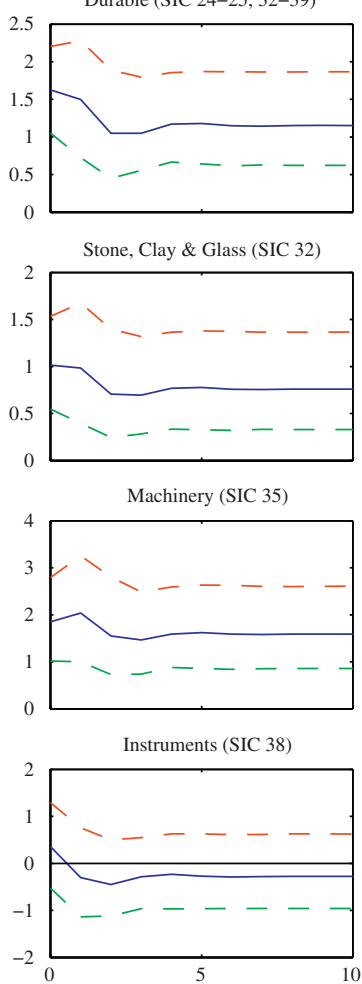


Petroleum Refining (SIC29)

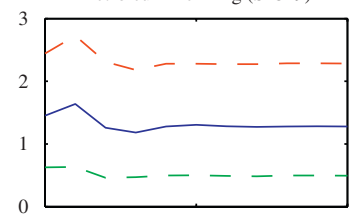

Lumber \& Wood Prod. (SIC 24)
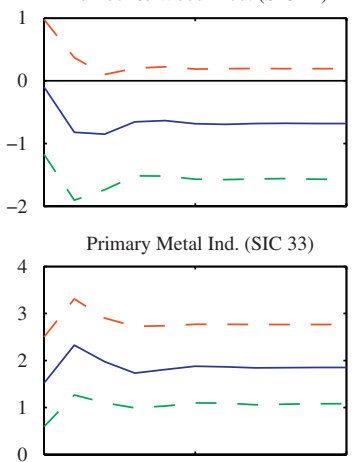

Electrical Machinery (SIC 36)
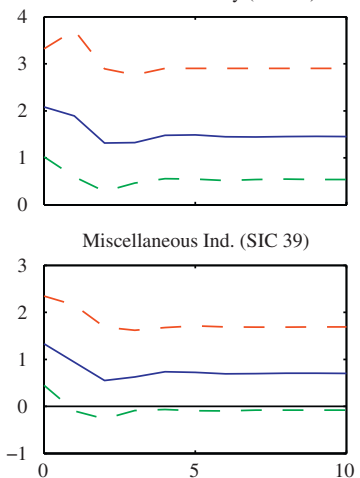

Fig. 7. Impulse responses of the labor productivity across industries to an investment-specific shock. 
by the shock. ${ }^{18}$ Thus, sectoral evidence seems to be consistent with the assumption of an economy-wide common source of fluctuations.

In contrast to the sector-neutral shock, technological changes affecting the production of investment goods determine heterogeneous effects across sectors (Fig. 7). After a positive shock, 12 out of 18 industries exhibit an increase in labor productivity both in the short run and in the long run. Specifically, the shock permanently affects five industries that are part of the nondurable-goods producing sector and seven industries that are part of the durable-goods producing sector. At a more aggregate level, however, a significant long-run effect is only estimated for the durable-goods producing sector. Indeed, this sector accounts for the positive effect displayed on impact and in the long run by manufacturing. Thus, we argue that sectoral results validate the interpretation of this shock as an investment-specific technological improvement.

A main feature of the US data is the near-zero correlation between aggregate hours and labor productivity growth rates. Both RBC and new Keynesian one-sector models explain this by assuming technology and non-technological sources of fluctuations that convey conditional correlations of opposite sign. A technology induced, positive correlation characterizes a standard RBC model, while a technology induced, negative correlation is mainly consistent with models based on nominal rigidities and variable labor effort or less orthodox versions of the RBC model. ${ }^{19}$

Our sectoral evidence reveals that the aggregate unconditional correlation hides strong sectoral correlations of opposite signs. Table 3 gives the unconditional correlations and the correlations conditional on the investment and neutral shocks for the three main aggregates considered (durable-goods, nondurable-goods and manufacturing sectors). ${ }^{20}$ The point estimate of the unconditional correlation for manufacturing is -0.16 , which is not statistically different from zero. Unconditional correlations relating to the durableand nondurable-goods sectors are estimated to be positive and negative, respectively, with the former being statistically different from zero. Sectoral conditional correlations provide, however, a clearer explanation of the lack of aggregate correlation. Arguably, this lack of correlation is the combined result of the positive correlation induced by the investment shocks in the durable-goods sector and the negative correlation determined by the sectorneutral shocks in the nondurable-goods sector. Indeed, formal tests support the idea that nondurable and durable goods have different correlations between hours worked and labor productivity, depending on the type of shock experienced. ${ }^{21}$ This result highlights that sectoral fluctuations provide a relevant piece of information to properly interpret

\footnotetext{
${ }^{18}$ It is interesting to note that we previously estimated no effect at all for the labor productivity of primary metal industries after an aggregate technology shock.

${ }^{19}$ King and Rebelo (2000) argue that a standard RBC model augmented with persistent exogenous technological shocks implies unconditional dynamic patterns for aggregate variables similar to those exhibited by actual time series. Looking, instead, at the conditional patterns of aggregate variables, Gali questions the validity of one-sector RBC model to explain business cycle. In particular, he argues that the nearly zero unconditional correlation should be interpreted as the outcome of the negative correlation due to technology shocks and the positive correlation due to demand shocks. Francis and Ramey (2005a) note, however, that some variants of a standard dynamic general equilibrium model, with habit formation in consumption and adjustment costs in investment or with a high degree of complementarity between inputs in the short run, produce the negative conditional correlation.

${ }^{20}$ For technical details on how to compute conditional correlations see Galí (1999).

${ }^{21}$ Results for hours, not reported, show that the investment shock determines positive and statistically significant effects across sectors at any horizons. Conversely, sectoral responses of hours to the neutral shock are
} 
Table 3

Conditional correlation estimates

\begin{tabular}{lccc}
\hline & Unconditional & \multicolumn{2}{l}{ Conditional } \\
\cline { 2 - 4 } & & Investment & Neutral \\
\hline Manufacturing & -0.16 & $0.52^{* *}$ & $-0.63^{* *}$ \\
& $(-1.12)$ & $(4.31)$ & $(-5.60)$ \\
Nondurable goods $(\rho 1)$ & $-0.32^{* *}$ & 0.18 & $-0.74^{* *}$ \\
& $(-2.32)$ & $(1.27)$ & $(-7.87)$ \\
Durable goods $(\rho 2)$ & 0.20 & $(7.46)$ & -0.22 \\
& $(1.42)$ & $-1.58)$ \\
Test of restriction: $\rho 1=\rho 2$ & & $-3.66^{* *}$ \\
$t$-Statistics & $-2.62^{* *}$ & $-3.56^{* *}$ \\
\hline Note: The table reports estimates of unconditional (data) and conditional correlations between the growth rates of \\
labor productivity and hours for manufacturing, nondurable- $(\rho 1)$ and durable $(\rho 2)$-goods producing sectors $(t-$ \\
statistics in brackets). In the last row we report the result of the hypothesis that the conditional correlations are \\
equal. Significance is indicated by one asterisk (10\% level) or two asterisks $(5 \%$ level).
\end{tabular}

aggregate evidence and addresses the need to look at sectoral models in order to improve our understanding of the business cycle. ${ }^{22}$

\section{Conclusions}

In this paper, we have estimated a DFM with data referring to the US manufacturing industries. Two distinct primitive shocks emerge as determining a substantial part of the variability in output and hours at business cycle frequencies. By adopting the assumption that technology shocks are those that determine permanent shifts in aggregate labor productivity, we find that a non-technological transitory shock is not long-run neutral across industries. Permanent effects are mainly detected in industries characterized by the production of durable goods. In principle, the aggregate transitory shock may be interpreted as a sectoral-shift innovation. However, to be consistent with the identification assumption, we should assume that its effects exactly cancel out on aggregate. Our suggested alternative interpretation is that the permanent component of the data tends not to be correctly recovered under the above identification assumption.

Sectoral estimates are more consistent with a framework characterized by sector-neutral and investment-specific shocks. Any shock may induce long-lasting effects on labor productivity. Under this identification assumption, we find that the investment shock permanently affects the labor productivity of the durable-goods producing sector, while its impact is not detected to be statistically significant in the nondurable-goods producing

\section{(footnote continued)}

often negative. Since the negative correlation holds for the nondurable-goods sector, one explanation rests on the possibility of habit persistence in consumption (Francis and Ramey, 2005a).

${ }^{22}$ Looking at a model that also distinguishes between shocks to the levels and growth rates of productivity in the consumption and investment sectors, Ireland and Schuh (2006) conclude that most of the productivity slowdown of the 1970s is attributed to the consumption-goods sector and suggest that the productivity slowdown of the investment-goods sector occurred later and was much less persistent. 
sector. Furthermore, we also find that a positive sector-neutral shock tends to permanently increase the labor productivity of almost all industries.

Sectoral data deliver a novel explanation of a well-known empirical puzzle, namely the near-zero correlation between aggregate labor productivity and employment growth rates. We show that the lack of unconditional correlation can be interpreted as the overall outcome of the positive and negative correlations that hold in the durable- and nondurable-goods producing sectors, respectively. The former correlation is determined by investment-specific shocks while the latter is traced to sector-neutral shocks. Further investigation is needed to improve the understanding of the sector-neutral shocks and to shed light on the mechanism that induces the conditional negative correlation within the nondurable-goods producing sector.

\section{Acknowledgmentts}

We are grateful to Domenico Giannone, Morten O. Ravn, Lucrezia Reichlin, Randall Verbrugge, the editor (Peter Ireland) and three anonymous referees for many helpful suggestions and discussions. We thank Efrem Castelnuovo, Jordi Galí, Marco Lippi, Bernd Lucke, Argia Sbordone, Paolo Surico, Guglielmo Weber, Philippe Weil and Michael Woodford for comments. We are also grateful to Jason Cummins and Gianluca Violante for the US price of equipment data. An earlier draft was written while the second author visited ECARES and circulated with the title Revisiting the one type permanent shocks hypothesis: aggregate fluctuations in a multi-sector economy. Saverio Simonelli acknowledges the RSCAS (EUI) for the financial support received as Jean Monnet fellow in the 2005-2006 European Forum program 'Growth Agenda for Europe'.

\section{Appendix A. Data description}

Labor is measured as the hours worked by all individuals engaged in a sector. Output in manufacturing industries (corresponding to the 2-digit standard industrial classification level) is based on the deflated value of production, less the portion which is consumed in the same industry. Real output aggregation is based on a chain-weight procedure.

The measure of output is consistent with a production function that represents the industry as if it were a single process. Intra-industry transactions are removed from all output and material input series used in this study, using transactions data contained in the various input-output tables for the US economy prepared by the US Bureau of Economic Analysis (BEA). It should be noted that the intrasector transaction for total manufacturing is greater than the sum of intra-sector transactions for 2-digit industries. For each 2-digit industry, intra-sector transactions are those between establishments in the same industry; for total manufacturing, the intrasector transaction consists of all shipments between domestic manufacturers, regardless of industry. $^{23}$

\footnotetext{
${ }^{23}$ For more details on data and variable definitions see Measurement Framework and Methods, Bureau of Labor Statistics, US Department of Labor, September 2000.
} 
The following list is comprised of sectors for which we have collected the above variables:

- manufacturing,

- nondurable goods,

- food and kindred products,

- textile mill products,

- apparel,

- paper and allied products,

- printing, publishing, and allied industries,

- chemicals and allied products,

- petroleum refining and related products,

- rubber and miscellaneous plastic products,

- durable goods,

- lumber and wood products (except furniture),

- furniture and fixtures,

- stone, clay, glass and concrete products,

- primary metal industries,

- fabricated metal products (except machinery),

- machinery (except electrical),

- electrical and electronic machinery, equipment and supplies,

- transportation equipment,

- measuring and controlling instruments,

- miscellaneous manufacturing industries.

The series of price is a ratio of the price of equipment and the consumption-goods deflator, constructed by Cummins and Violante (2002).

\section{References}

Bai, J., Ng, S., 2000. Determining the number of factors in approximate factor models. Econometrica 70, 191-221.

Bai, J., Ng, S., 2007. Determining the number of primitive shocks in factor models. Journal of Business and Economic Statistics 25 (1), 52-60.

Blanchard, O.J., Quah, D., 1989. The dynamic effect of aggregate demand and supply disturbances. American Economic Review 79, 655-673.

Boldrin, M., Christiano, L.J., Fisher, J.D.M., 2001. Habit persistence, asset returns, and the business cycle. American Economic Review 91 (1), 149-166.

Campbell, J.R., Kuttner, K.N., 1996. Macroeconomic effects of employment reallocation. Carnegie-Rochester Conference Series on Public Policy 44, 87-116.

Chang, Y., Hong, J.H., 2005. Do technological improvements in the manufacturing sector raise or lower employment? American Economic Review 96 (1), 352-368.

Cummins, J.G., Violante, G.L., 2002. Investment-specific technical change in the US (1947-2000): measurement and macroeconomic consequences. Review of Economic Dynamics 5 (2), 243-284.

Davis, S.J., Haltiwanger, J., 1999. On the driving forces behind cyclical movements in employment and job reallocation. American Economic Review 89 (5), 1234-1258.

Erceg, C., Guerrieri, L., Gust, C., 2005. Can long-run restrictions identify technology shocks? Journal of the European Economic Association 3 (6), 1237-1278.

Fisher, J.D.M., 2006. The dynamic effects of neutral and investment-specific technology shocks. Journal of Political Economy 114 (3), 413-451. 
Forni, M., Hallin, M., Lippi, M., Reichlin, L., 2000. The generalized dynamic factor model: Identification and estimation. Review of Economics and Statistics 82 (4), 540-554.

Forni, M., Giannone, D., Lippi, M., Reichlin, L., 2007. Opening the black box-structural factor models with large gross-sections. Working Paper Series 712, European Central Bank.

Francis, N., Ramey, V.A., 2005a. Is the technology-driven real business cycle hypothesis dead? Shocks and aggregate fluctuations revisited. Journal of Monetary Economics 52 (8), 1379-1399.

Francis, N., Ramey, V.A., 2005b. Measures of per capita hours and their implications for the technology-hours debate. NBER Working Papers 11694, National Bureau of Economic Research, Inc.

Galí, J., 1999. Technology employment and the business cycle: do technology shocks explain aggregate fluctuations? American Economic Review 89 (1), 249-271.

Galí, J., 2005. Trends in hours balanced growth and the role of technology in the business cycle. Review-Federal Reserve Bank of St. Louis 459-486.

Galí, J., Rabanal, P., 2005. Technology shocks and aggregate fluctuation: how well does the RBD model fit postwar US data? In: NBER Macroeconomics Annual 2004. The MIT Press, Cambridge, MA pp. 161-200.

Greenwood, J., Hercowitz, Z., Krusell, P., 1997. Long-run implications of investment-specific technological change. American Economic Review 87 (3), 342-362.

Greenwood, J., Hercowitz, Z., Krusell, P., 2000. The role of investment-specific technological change in the business cycle. European Economic Review 44 (1), 91-115.

Hornstein, A., Praschnik, J., 1997. Intermediate inputs and sectoral comovement in the business cycle. Journal of Monetary Economics 40 (3), 573-595.

Horvath, M., 2000. Sectoral shocks and aggregate fluctuations. Journal of Monetary Economics 45 (1), 69-106.

Horvath, M., Verbrugge, R., 1997. Shocks and sectoral interactions: an empirical investigation. Mimeo, Stanford University.

Ireland, P.N., Schuh, S., 2006. Productivity and U.S. macroeconomic performance: interpreting the past and predicting the future with a two-sector real business cycle model. Boston College Working Papers in Economics 642, Boston College Department of Economics.

Kiley, M.T., 1997. Labor productivity in U.S. manufacturing: does sectoral comovement reflect technology shocks. Mimeo, Federal Reserve Board, Washington, DC.

King, R.G., Rebelo, S.T., 2000. Resuscitating real business cycles. NBER Working Papers 7534, National Bureau of Economic Research, Inc.

Lilien, D.M., 1982. Sectoral shifts and cyclical unemployment. Journal of Political Economy 90 (4), 777-793.

Long, J., Plosser, C., 1987. Sectoral vs. aggregate shocks in the business cycles. American Economic Review 91 (2), 333-336.

Long, J.B., Plosser, C.I., 1983. Real business cycles. Journal of Political Economy 91 (1), 39-69.

Onatski, A., 2007. A formal statistical test for the number of factors in the approximate factor models, Columbia University, Mimeo.

Pelloni, G., Polasek, W., 2003. Macroeconomic effects of sectoral shocks in Germany, the U.K. and the U.S. A var-garch- $m$ approach. Computational Economics 21 (1), 65-85.

Phelan, C., Trejos, A., 2000. The aggregate effects of sectoral reallocations. Journal of Monetary Economics 45 (2), 249-268.

Ramey, V., 1996. Can technology improvements cause productivity slowdowns? Comment. In: NBER Macroeconomics Annual 1996. The MIT Press, Cambridge, MA, pp. 268-274.

Stock, J.H., Watson, M.W., 2002. Macroeconomic forecasting using diffusion indexes. Journal of Business and Economic Statistics 40, 147-162.

Whelan, K., 2003. A two-sector approach to modeling U.S. NIPA data. Journal of Money, Credit and Banking 35 (4), 627-656. 